\title{
ANTOCIANINAS EM SUCO DE UVA: COMPOSIÇÃO E ESTABILIDADE
}

\author{
CASSIA ROBERTAMALACRIDA* \\ SILVANADA MOTTA
}

\begin{abstract}
Neste trabalho de revisão da literatura, a composição e a estabilidade de antocianinas em suco de uva foram estudadas. Aspectos referentes à influência das diversas etapas do processamento na degradação das antocianinas foram abordados. Uma breve revisão sobre os métodos de análise quantitativa e qualitativa de antocianinas também foi apresentada. Além da composição inicial da matéria-prima, a composição de antocianinas no suco é influenciada por diversos fatores, tais como $\mathrm{pH}$, temperatura e presença de luz e oxigênio durante o processamento. Maiores estudos para avaliar e aumentar a estabilidade de antocianinas são ainda necessários, visando maior aplicabilidade desses compostos em alimentos processados.
\end{abstract}

PALAVRAS-CHAVE: ANTOCIANINAS; UVA; SUCO DE UVA.

\section{INTRODUÇÃO}

As antocianinas (das palavras gregas anthos, flor e kianos, azul) são pigmentos vegetais responsáveis pela maioria das cores azul, roxa e todas as tonalidades de vermelho encontradas em flores, frutos, algumas folhas, caules e raízes de plantas (MARKAKIS, 1982). São compostos solúveis em água e altamente instáveis em temperaturas elevadas (SHAHIDI e NACZK, 1995).

* Mestre em Ciência de Alimentos, Departamento de Alimentos, Faculdade de Farmácia, Universidade Federal de Minas Gerais (UFMG) (e-mail: cmalacrida@uol.com.br).

** Doutora em Ciência de Alimentos, Professora do Departamento de Alimentos, Faculdade de Farmácia, UFMG, Av. Antônio Carlos no 6627, CEP 31270-010, Belo Horizonte-MG.

B.CEPPA, Curitiba, v. 24, n. 1, p. 59-82 jan./jun. 2006 
As antocianinas fazem parte do grupo dos flavonóides, compostos fenólicos caracterizados pelo núcleo básico flavílio (cátion 2-fenilbenzopirílio) que consiste de dois anéis aromáticos unidos por uma unidade de três carbonos e condensada por um oxigênio. A molécula de antocianina (Figura 1) é constituída por duas ou três porções, uma aglicona (antocianidina), um grupo de açúcares e, freqüentemente, um grupo de ácidos orgânicos (FRANCIS, 1989). Aproximadamente 22 agliconas são conhecidas, das quais 18 ocorrem naturalmente e apenas seis (pelargonidina, cianidina, delfinidina, peonidina, petunidina e malvidina) são importantes em alimentos (FRANCIS, 2000).

\section{FIGURA 1 - ESTRUTURAS QUIIMICAS DAS ANTOCIANINAS}<smiles>[R7]c1cc(-c2[o+]c3cc(O)cc(O)c3cc2OC2O[C@H](CO)[C@@H](O)[C@H](O)C2O)cc([R7])c1O</smiles>

\section{Aglicona \\ (Estrutura do anel B)}

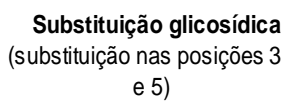

e 5)

$\mathrm{R}_{1}=\mathrm{R}_{2}=\mathrm{H}$

$\mathrm{R}_{1}=\mathrm{OH}, \mathrm{R}_{2}=\mathrm{H}$

$\mathrm{R}_{1}=\mathrm{R}_{2}=\mathrm{OH}$

$\mathrm{R}_{1}=\mathrm{OCH}_{3}, \mathrm{R}_{2}=\mathrm{H}$

$\mathrm{R}_{1}=\mathrm{OCH}_{3}, \mathrm{R}_{2}=\mathrm{OH}$

$\mathrm{R}_{1}=\mathrm{R}_{2}=\mathrm{OCH}_{3}$
D-glicose

D-galactose

D-xilose

L-ramnose

L-arabinose

Rutinose

Soforose

Sambubiose

Gentiobiose
Acilação

(esterificação das hidroxilas do açúcar)

Ácidos cinâmicos

p-cumárico

Ferúlico

Caféico

Ácidos alifáticos

Acético

Malônico

Succínico

Antocianidinas livres são raramente encontradas em plantas, ocorrendo comumente glicosiladas com açúcares que estabilizam a molécula (FRANCIS, 2000). A glicosilação pode ocorrer em várias posições, sendo observada com maior freqüência na posição 3 . O segundo açúcar 
quando presente na molécula encontra-se na posição 5 , porém podem ocorrer glicosilações nas posições 7, 3', 4' e 5' (BROUILLARD, 1982). Glicose, ramnose, xilose, galactose, arabinose e frutose são os açúcares mais comumente ligados às antocianidinas, ocorrendo como monoglicosídios, diglicosídios e triglicosídios glicosilados diretamente na aglicona (FRANCIS, 1989).

Muitas vezes, os açúcares das antocianinas são acilados pelos ácidos p-cumárico, ferúlico, caféico, p-hidroxibenzóico, sinápico, malônico, acético, succínico, oxálico e málico (FRANCIS, 1989). Os substituintes acila encontram-se usualmente ligados à hidroxila do açúcar na posição 3 e com menor freqüência nas posições 4 e 6 . A metoxilação é mais freqüente nas posições 3' e 5' e menos comum em na 5 e na 7 . É importante salientar que antocianina natural nunca apresenta as hidroxilas das posições 5, 7 e 4' substituídas ao mesmo tempo. Um dos grupos hidroxila deve permanecer livre numa dessas posições para a formação da estrutura quinoidal, responsável pela cor (BROUILLARD, 1982).

O objetivo deste trabalho foi apresentar uma revisão sobre a composição, estabilidade e métodos de análise de antocianinas em suco de uva.

\section{FONTES, FUNÇÕES E APLICAÇÕES DAS ANTOCIANINAS}

Existem aproximadamente 400 antocianinas diferentes (KONG et al., 2003). Segundo JACKMAN e SMITH (1996), as antocianinas encontram-se distribuídas em numerosas famílias de plantas: Vitaceae (uva), Rosaceae (cereja, ameixa, framboesa, morango, amora, maçã, pêssego, etc.), Solanaceae (tamarindo, batata), Saxifragaceae (groselha preta e vermelha), Ericaceae (mirtilo, oxicoco), Cruciferae (repolho roxo, rabanete), Leguminoseae (vagem) e Gramineae (sementes de cereais). $\mathrm{Na}$ Tabela 1 constam diferentes antocianinas e suas fontes.

Além de contribuir para a cor de flores e frutas, as antocianinas atuam como filtro das radiações ultravioletas nas folhas. Em certas espécies de plantas estão associadas com a resistência aos patógenos e atuam melhorando e regulando a fotossíntese (MAZZAe MINIATI, 1993). 


\section{TABELA 1 - ANTOCIANINAS ENCONTRADAS COM FREQÜÊNCIA EM ALIMENTOS E SUAS FONTES}

\begin{tabular}{ll}
\hline \multicolumn{1}{c}{ Antocianinas } & \multicolumn{1}{c}{ Fonte } \\
\hline Cianidina-3-glicosídio & Uva, vinho, cereja, jambolão, morango, amora, maçã, azeitona \\
Cianidina-3,5-diglicosídio & Uva, vinho, cereja, figo, marmelo \\
Peonidina-3-glicosídio & Uva, vinho, cereja, jabuticaba \\
Malvidina-3-glicosídio & Uva, vinho \\
Malvidina-3,5-diglicosídio & Uva, vinho, feijão, inhame \\
Cianidina-3-galactosídio & Maçã, cacau \\
Cianidina-3p-cumarilsoforosídio-5-glicosídio Repolho roxo \\
Pelargonidina-3-soforosídio-5-glicosídio & Rabanete \\
Pelargonidina-3-glicosídio & Morango, tamarindo \\
Delfinidina-3,5-diglicosídio & Berinjela, feijão, uva, romã \\
Delfinidina-3-cafeoilglicosídio-5-glicosídio & Berinjela \\
Petunidina-3-glicosídio & Uva, vinho, feijão, mirtilo, laranja \\
\hline
\end{tabular}

Em alimentos industrializados, as antocianinas são empregadas como corantes naturais. Entretanto, sua utilização ainda é restrita pela baixa estabilidade em meios aquosos e $\mathrm{pH}$ acima de 2, condições bastante comuns durante o processamento e estocagem dos alimentos (FALCÃO et al., 2003; FRANCIS, 1989).

Apesar de largamente disseminadas na natureza são poucas as fontes comercialmente utilizáveis de antocianinas. Entre essas fontes podese citar o resíduo da fabricação do vinho e do suco de uva que produz o pigmento usado em alimentos com o nome de enocianina (BOBBIO e BOBBIO, 2001).

As antocianinas também apresentam propriedades farmacológicas, sendo utilizadas para fins terapêuticos. Já foram comprovados cientificamente seus efeitos anticarcinogênico (HAGIWARA et al., 2001, KAMEl et al., 1998), antioxidante (WANG et al., 2000; YOUDIM, MARTIN e JOSEPH, 2000) e antiviral (KAPADIA et al., 1997).

KUSKOSKI et al. (2004) estudaram a atividade antioxidante de pigmentos antociânicos em temperatura ambiente por meio do método de descoloração do radical $\mathrm{ABTS}^{+}$(2,2'-azino-bis-3-etilbenzotiazolina6 -sulfonato). Os resultados obtidos demonstraram que estes pigmentos apresentam atividade antioxidante potencial, a qual varia conforme as 
diferentes substituições hidroxílicas e metoxílicas na molécula. Das antocianinas analisadas, agliconas com dois grupamentos $\mathrm{OH}$ substituídos no anel B (pelargonidina-3-glicosídio, peonidina-3-glicosídio e malvidina-3-glicosídio) apresentaram maior atividade antioxidante do que aqueles com apenas um grupo $\mathrm{OH}$ no anel $\mathrm{B}$ (delfinidina $\mathrm{e}$ cianidina-3-glicosídio).

\section{ESTABILIDADE DAS ANTOCIANINAS}

De acordo com FRANCIS (1989), os principais fatores que influenciam a estabilidade das antocianinas são a estrutura química, o pH, a temperatura, a luz, a presença de oxigênio, a degradação enzimática e as interações entre os componentes dos alimentos, tais como ácido ascórbico, íons metálicos, açúcares e copigmentos.

As antocianidinas são menos estáveis do que as antocianinas. A cianidina-3-glicosídio, por exemplo, apresenta tempo de meia-vida em solução de ácido cítrico $0,01 \mathrm{M}(\mathrm{pH} 2,8)$ de 65 dias, enquanto que sua aglicona livre alcança apenas 12 horas nas mesmas condições (IACOBUCCI e SWEENY, 1983).

O grau de hidroxilação exerce importante efeito na estabilidade das antocianinas, sendo que aquelas que contém mais grupos hidroxilas em sua estrutura são menos estáveis. Inversamente, alto grau de metoxilação aumenta a estabilidade das antocianinas (FRANCIS, 1989). O aumento no número de hidroxilas fenólicas muda a coloração das antocianinas de rosa para azul, sendo que a presença de grupos metoxila no lugar de hidroxilas reverte a tendência anterior (MAZZA e BROUILLARD, 1987).

$\mathrm{O} \mathrm{pH}$ exerce profunda influência na cor das antocianinas, assim como na sua estabilidade. As antocianinas são mais estáveis em soluções ácidas do que em neutras e alcalinas (MARKAKIS, 1982). Em solução aquosa, segundo BROUILLARD e DUBOIS (1977) podem existir quatro formas estruturais de antocianinas em equilíbrio (Figura 2): o cátion flavílio $\left(\mathrm{AH}^{+}\right)$, a base quinoidal $(\mathrm{A})$, a pseudobase ou carbinol (B) e a chalcona $(\mathrm{C})$. Em condições ácidas ( $\mathrm{pH}$ inferior a 2), a antocianina existe primariamente na forma de cátio flavílio $\left(\mathrm{AH}^{+}\right)$de cor vermelha. Elevando-se $\mathrm{o} \mathrm{pH}$ ocorre a rápida perda do próton para produzir as 
formas quinoidais $(A)$, azuis ou violetas. Em paralelo ocorre a hidratação do cátion flavílio $\left(\mathrm{AH}^{+}\right)$, gerando a pseudobase incolor ou carbinol (B) que atinge o equilíbrio lentamente com a chalcona incolor $(C)$. As quantidades relativas de cátion $\left(\mathrm{AH}^{+}\right)$, formas quinoidais $(\mathrm{A})$, pseudobase (B) e chalcona $(C)$ na condição de equilíbrio variam conforme o $\mathrm{pH}$ e a estrutura da antocianina (IACOBUCCI e SWEENY, 1983).

As antocianinas são rapidamente destruídas pelo aquecimento durante o processamento e estocagem de alimentos. Muitos estudos demonstraram relação logarítmica entre a destruição das antocianinas e o aumento aritmético da temperatura. Processos utilizando baixo tempo em alta temperatura têm sido recomendados para melhor retenção dos pigmentos. No caso de sucos de frutas vermelhas, perdas de antocianinas mostraram-se insignificantes para tratamentos térmicos com duração inferior a 12 minutos a $100^{\circ} \mathrm{C}$ (MARKAKIS, 1982).

MESCHTER (1954) verificou a destruição de 50\% das antocianinas durante o processamento de compota de morango a $100^{\circ} \mathrm{C}$. Ao longo da estocagem a 38 e $20^{\circ} \mathrm{C}$, o tempo de meia-vida das antocianinas foi de 10 e 54 dias, respectivamente. Por extrapolação, obteve tempo de meia-vida de 11 meses a $0^{\circ} \mathrm{C}$.

O mecanismo da degradação térmica das antocianinas ainda não foi completamente elucidado. ADAMS (1973) mostrou que para valores de $\mathrm{pH}$ entre 2,0 e 4,0, o aquecimento das antocianinas provoca primeiramente a hidrólise da ligação glicosídica com posterior formação da chalcona. Além disso, existem evidências de que a hidrólise glicosídica das antocianinas seja a principal causa da perda de cor, uma vez que a velocidade da liberação do açúcar é proporcional à velocidade da perda da cor vermelha.

BROUILLARD (1982) estudou a estabilidade das antocianinas em solução durante aquecimento. Verificou deslocamento do equilíbrio no sentido da formação de chalcona $(C)$, resultando em decréscimo nas formas coloridas da base quinoidal $(\mathrm{A})$ e do cátion flavílio $\left(\mathrm{AH}^{+}\right)$. Após resfriamento e acidificação, as formas $(A)$ e $(B)$ são rapidamente transformadas na forma catiônica $\left(\mathrm{AH}^{+}\right)$, mas a conversão da forma chalcona $(C)$ para $(B)$ é mais lenta que a reação inversa (Figura 2 ). 


\section{FIGURA 2 - FORMAS ESTRUTURAIS DE ANTOCIANINAS EM EQUILÍBRIO EM SOLUÇÃO AQUOSA}<smiles>[R]c1cc(-c2oc3cc(=O)cc(O)c-3cc2OC)cc([R])c1O</smiles>

Base quinoidal $(\mathrm{A})$

Azul<smiles>[R]c1cc(C(=O)/C(=C\c2c(O)cc(O)cc2O)OCl)cc([R])c1O</smiles>

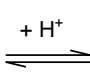

$\mathrm{HO}$<smiles>[R]c1cc(-c2[o+]c3cccc(O)c3cc2OCl)cc([R])c1O</smiles>

Cátion flavílio $\left(\mathrm{AH}^{+}\right)$

Vermelho

$\| \begin{gathered}+\mathrm{H}_{2} \mathrm{O} \\ -\mathrm{H}^{+}\end{gathered}$<smiles>[R]c1cc(C2(O)Oc3cc(O)cc(O)c3C=C2OCCl)cc([R])c1O</smiles>

Carbinol (B)

Incolor

Fonte: FRANCIS (1989).

KIRCA, ÖZKAN e CEMEROGLU (2006) estudaram a estabilidade de antocianinas da cenoura adicionadas em sucos (maçã, laranja, uva, grapefruit, tangerina e limão) e néctares (damasco, pêssego e abacaxi), durante aquecimento a $70-90^{\circ} \mathrm{C}$ e estocagem a $4-37^{\circ} \mathrm{C}$. Os resultados demonstraram grande efeito da temperatura de estocagem na estabilidade das antocianinas em todos os sucos e néctares, ocorrendo degradação muito mais rápida durante estocagem a $37^{\circ} \mathrm{C}$. As antocianinas apresentaram menor estabilidade durante aquecimento e estocagem no suco de laranja. Com relação ao aquecimento, as antocianinas nos sucos de maçã e uva e nos néctares de damasco e 
pêssego revelaram maior estabilidade a 70 e $80^{\circ} \mathrm{C}$.

As antocianinas são geralmente instáveis quando expostas à luz ultravioleta e visível, ou outras fontes de radiação ionizante. As antocianinas substituídas no grupo hidroxílico do C-5 são mais susceptíveis a decomposição fotoquímica do que as não substituídas nessa posição (IACOBUCCI e SWEENY, 1983).

PALAMIDIS e MARKAKIS (1975) observaram que a presença de luz acelerou a destruição das antocianinas em bebidas carbonatadas, coloridas com antocianinas extraídas da polpa da uva. O tempo de meia-vida das antocianinas $a 20^{\circ} \mathrm{C}$ no escuro foi de 416 dias, diminuindo para 197 dias quando as bebidas foram expostas à luz ambiente nas mesmas condições de temperatura.

O efeito do oxigênio na degradação das antocianinas foi descoberto por TRESSLER e PEDERSON (1936). Esses autores observaram que a mudança da cor roxa para marrom em sucos de uva engarrafados podia ser prevenida simplesmente enchendo-se completamente as garrafas, ou seja, eliminando o oxigênio do seu interior.

O oxigênio pode causar degradação das antocianinas por mecanismos de oxidação direta ou indireta, quando constituintes oxidados do meio reagem com as antocianinas (JACKMAN e SMITH, 1996). O peróxido de hidrogênio $\left(\mathrm{H}_{2} \mathrm{O}_{2}\right)$, formado pela oxidação do ácido ascórbico na presença de oxigênio e íons cobre, causa descoloração das antocianinas. Tal fato, leva a crer que a degradação das antocianinas nessas condições seja mediada pelo $\mathrm{H}_{2} \mathrm{O}_{2}$. Outra alternativa para explicar sua degradação é a ocorrência da reação de condensação entre o ácido ascórbico e a antocianina, formando produtos instáveis que se degradam em compostos incolores (MARKAKIS, 1982).

O anidrido sulfuroso e os sulfitos utilizados na conservação de alimentos a base de frutas produzem efeito descolorante sobre as antocianinas. Isto se deve a adição desses compostos nas posições 2 ou 4 com a formação de estruturas sulfônicas que são incolores. A reação é reversível, podendo a cor ser regenerada por acidificação ou aquecimento do produto. Entretanto, altas concentrações de sulfito, maiores que $10 \mathrm{~g} / \mathrm{kg}$, provocam destruição irreversível das antocianinas (ARAÚJO, 1995; DERGAL,1993). 
As antocianinas também podem ser degradadas por enzimas endógenas presentes nos tecidos das plantas, tais como glicosidases, polifenol oxidases e peroxidases. As glicosidases, também denominadas antocianases, hidrolizam as ligações glicosídicas com a liberação do açúcar e da aglicona. Essa última é instável e degradase espontaneamente formando a chalcona incolor. As polifenol oxidases atuam pelo mecanismo de oxidação, usando como substratos 0 dihidroxifenóis. As o-quinonas resultantes podem reagir entre si ou com outros compostos, inclusive antocianinas, e formar polímeros escuros. As fenolases podem reagir diretamente com as antocianinas embora a reação seja mais favorecida quando outros fenólicos (que são melhores substratos para essas enzimas) estão presentes (FRANCIS, 1989).

MESCHTER (1954) pesquisou o efeito do açúcar sobre a degradação das principais antocianinas do morango. Frutose, arabinose, lactose e sorbinose mostraram-se mais deletérias aos pigmentos do que a sacarose, glicose e maltose. A presença de oxigênio agravou os efeitos destrutivos dos açúcares. Segundo o mesmo autor, a decomposição dos pigmentos está relacionada com a presença de furfural (originado principalmente de aldo-cetoses) e 5-hidroximetilfurfural (originado de ceto-hexoses), produtos resultantes da degradação de açúcares pela reação de Maillard ou pela oxidação do ácido ascórbico. Esses compostos facilmente condensam-se ou reagem com as antocianinas, possivelmente via ataque eletrofílico, formando compostos de coloração marrom.

Diferentes íons metálicos polivalentes interagem com antocianinas que contêm hidroxilas na posição orto, produzindo alteração na cor do pigmento para azul (MARKAKIS, 1982). Os metais atuam quelando as antocianinas numa estrutura quinoidal estável quando o $\mathrm{pH}$ se encontra na faixa de 3,0 a 6,0, valores comuns em sucos de frutas (STARR e FRANCIS, 1973).

Em meio aquoso as antocianinas formam complexos com numerosos compostos tais como proteínas, taninos, flavonóides não-antociânicos, ácidos orgânicos, ácidos nucléicos, alcalóides, polissacarídios e íons metálicos por meio de copigmentação intermolecular (BROUILLARD, 1982; OSAWA, 1982). Tanto o cátion flavílio quanto a base quinoidal podem participar da copigmentação. A copigmentação envolvendo 
essas duas estruturas resulta em deslocamento batocrômico no comprimento de onda de absorção máxima na faixa visível do espectro do vermelho para o azul (ASEN; STEWART e NORRIS, 1972). Os copigmentos mais eficientes são os flavonóis (quercetina e rutina), uma aurona (auresidina) e, principalmente, as C-glicosil flavonas (SOMERS e EVANS, 1977).

A associação das antocianinas com copigmentos ocorre por meio de ligações de hidrogênio ou do processo de empilhamento das moléculas mediante interações hidrofóbicas (MAZZA e BROUILLARD, 1987). Esse empilhamento proporciona eficiente proteção aos cromóforos de antocianinas contra o ataque nucleofílico e, especialmente, a hidratação e perda de cor (JACKMAN e SMITH, 1996). Desta forma, a copigmentação é considerada como processo seletivo das formas coloridas (BROUILLARD et al., 1989).

A copigmentação intermolecular parece ser menos eficiente na estabilização dos cromóforos de antocianinas do que a copigmentação intramolecular, que ocorre pela acilação, ainda que em nível molecular as características de ambos os fenômenos sejam similares (JACKMAN e SMITH, 1996).

SARNI-MANCHADO et al. (1996) estudaram a estabilidade de antocianinas não-aciladas no extrato bruto de uva (Vitis vinifera). $\mathrm{O}$ estudo foi realizado em pH 3,0 e 5,0 na presença de oxigênio e ausência de luz a $55^{\circ}$ C. Após 8 dias foi verificada redução de $80-90 \%$ da cor inicial das soluções, indicando a pouca estabilidade das antocianinas não-aciladas nas condições testadas.

\section{ANTOCIANINAS NA UVA E NO SUCO DE UVA}

A quantidade e a composição das antocianinas presentes nas uvas diferem de acordo com a espécie, variedade, maturidade, condições climáticas e cultivar. O conteúdo de antocianinas em uvas tintas varia de 30 a $750 \mathrm{mg}$ por $100 \mathrm{~g}$ da fruta madura. Em uvas Concord varia entre $61-112 \mathrm{mg} / 100 \mathrm{~g}$, enquanto que uvas viníferas como Pinot Noir, Cabernet Sauvignon e Vincent apresentam concentrações médias de antocianinas de 33, 92 e $439 \mathrm{mg} / 100 \mathrm{~g}$, respectivamente (MAZZA, 1995). 
As uvas contêm complexa variedade de antocianinas. VAN BUREN et al. (1970) examinaram os pigmentos de 151 variedades de uvas híbridas e encontraram como antocianinas predominantes a malvidina monoglicosídio e a malvidina diglicosídio. Segundo RIBÉREAU-GAYON (1982), as principais antocianinas presentes em uvas da espécie Vitis rotundifolia (variedade Muscadine) são 3,5-diglicosídio de malvidina, peonidina, cianidina, petunidina e delfinidina, sendo que as duas últimas perfazem juntas $67 \%$ do total de antocianinas.

GOLDY, BALLINGER e MANESS (1986) verificaram a presença de 31 antocianinas diferentes em uvas da espécie Vitis labrusca (variedade Concord). Desse total, apenas 12 foram completamente caracterizadas: 3-glicosídio e 3,5-diglicosídio de cianidina, 3-glicosídio e 3,5-diglicosídio de peonidina, 3-glicosídio e 3,5-diglicosídio de delfinidina, 3-glicosídio e 3,5-diglicosídio de petunidina, 3-glicosídio e 3,5-diglicosídio de malvidina, 3- acetilglicosídio de malvidina e 3-pcumarilglicosídio de malvidina.

O suco de uva apresenta pouca diferença na composição de antocianinas em relação às uvas frescas. O suco preparado a partir de uvas da variedade Concord apresenta como principais antocianinas cianidina, peonidina, delfinidina, petunidina e malvidina, todas na forma de mono e diglicosídios. A cianidina-3-glicosídio e a delfinidina-3glicosídio são as antocianinas encontradas em maiores quantidades no suco de uva (HRAZDINA, 1975; WANG e SPORNS, 1999).

Durante o processamento do suco ocorrem perdas na quantidade total de antocianinas e, conseqüentemente, na sua coloração. Tal fato devese aos tratamentos que a uva e o mosto são submetidos durante a produção do suco, tais como aquecimento, prensagem, pasteurização e tratamentos enzimáticos (SISTRUNK e GASCOIGNE, 1983).

MALACRIDA (2003) determinou a concentração de antocianinas em sucos de uva reconstituídos e simples disponíveis comercialmente. Os sucos de uva simples apresentaram maiores concentrações médias de antocianinas $(28,7 \mathrm{mg} / \mathrm{L})$ quando comparados aos sucos reconstituídos (17,3 mg/L). Diferenças nos processamentos dos sucos podem ter contribuído para as distintas quantidades de antocianinas encontradas, uma vez que o suco reconstituído é elaborado a partir da 
diluição do suco concentrado de uva.

Vigoroso esmagamento aumenta a extração e difusão das antocianinas e outros compostos fenólicos. Entretanto, resulta em sucos muito adstringentes e amargos. Além disso, a oxidação enzimática dos compostos fenólicos aumenta podendo levar ao escurecimento do suco e ao desenvolvimento de características sensoriais indesejáveis (MAZZA, 1995).

Embora a extração a quente facilite a solubilização das antocianinas da casca da uva para o suco, o aquecimento excessivo deve ser evitado. Longos períodos de extração em altas temperaturas podem acarretar decréscimo das antocianinas do suco devido reações de degradação ou condensação com taninos (RIBÉREAU-GAYON, 1982). O total de antocianinas que é de aproximadamente $460 \mathrm{mg} / 100 \mathrm{~g}$ de suco extraído a frio diminui para $200 \mathrm{mg} / 100 \mathrm{~g}$ de suco quando a extração ocorre a quente (MAZZA, 1995). Além disso, tempos longos de contato entre as partes sólidas da uva e o suco podem provocar alterações nos conteúdos de antocianinas devido à adsorção e/ou desorção dessas moléculas pelo bagaço da uva (MAZZA, 1995). O rendimento máximo na extração da cor é alcançado após duas horas de tratamento do mosto. Diferenças podem ser verificadas nesse tempo, dependendo do tipo de extração realizada e do uso ou não de preparações enzimáticas durante o processamento (HOFSOMMER, 1995).

O suco intersticial, rico em compostos fenólicos, é extraído durante a etapa de prensagem e o conteúdo de antocianinas no suco chega a alcançar $700-800 \mathrm{mg} / \mathrm{L}$. O suco intersticial contém, além de antocianinas livres, diferentes antocianinas complexadas com taninos (RIBÉREAU-GAYON, 1982).

Enzimas pécticas são usadas na produção de suco de uva para facilitar a clarificação. Foi demonstrado que preparações comerciais de enzimas pécticas provocam decréscimo no conteúdo total de antocianinas e na intensidade de cor de vinhos. As enzimas comerciais são tipicamente preparações fúngicas, contendo impurezas como enzimas estranhas, proteínas e mucilagens. Essas enzimas contêm $\beta$-glicosidase e podem quebrar a ligação glicosídica, liberando o açúcar 
das antocianinas e originando aglicona menos colorida (WIGHTMAN et al.,1997).

Durante a produção de suco de uva há formação de bitartarato de potássio, o qual é separado do suco por decantação e filtragem. Nessa etapa, o suco é resfriado e estocado em tanques por 6-8 dias para precipitação do bitartarato. A estocagem em baixa temperatura provoca alteração na cor do suco de uva em razão de mudanças no $\mathrm{pH}$ e precipitação de antocianinas complexadas (MAZZA, 1995).

Altas temperaturas, durante o processamento e estocagem do suco, podem provocar mudanças nas características da cor do produto. A formação da chalcona (incolor) é favorecida pelo aumento da temperatura, que acarreta perda de cor no suco de uva (JACKMAN e SMITH, 1996). Tem-se recomendado o uso de altas temperaturas por curto período de tempo para maximizar a retenção de pigmentos durante os tratamentos térmicos aos quais o suco é submetido em seu processamento. Tempos curtos de aquecimento podem prevenir a degradação das antocianinas e/ou sua transformação em estruturas incolores (DERGAL, 1993; ROMMEL, WROLSTAD e HEATHERBELL, 1992).

HOFSOMMER (1995) investigou alterações na constituição antociânica de 60 amostras de suco de uva tinto durante as etapas de processamento. As maiores perdas foram verificadas durante a pasteurização realizada a $90^{\circ} \mathrm{C}$ por dez minutos. O decréscimo na quantidade de antocianinas ficou próximo a 50\%. O tempo e a temperatura de estocagem também provocaram alterações na quantidade de antocianinas do suco. Maiores perdas foram verificadas em maior tempo de estocagem.

O decréscimo no conteúdo de antocianinas durante a estocagem devese a formação de pigmentos poliméricos, os quais são menos sensíveis a mudanças de $\mathrm{pH}$ e mais resistentes à descoloração por dióxido de enxofre $\left(\mathrm{SO}_{2}\right)$. Freqüentemente esses pigmentos poliméricos resultam da condensação direta entre antocianinas e flavonóis (FRANCIAARICHA et al., 1997). Muitas vezes são formados grandes agregados poliméricos, que podem sedimentar durante longo período de armazenamento e formar precipitados escuros (DERGAL,1993). 


\section{MÉTODOS DE ANÁLISE QUALITATIVA E QUANTITATIVA DE ANTOCIANINAS}

Vários são os métodos existentes para qualificar e quantificar antocianinas em alimentos. Todos esses métodos necessitam extração prévia das antocianinas dos alimentos a serem analisados.

As antocianinas, em $\mathrm{pH}$ baixo, encontram-se predominantemente na forma de cátion flavílio, o qual apresenta coloração vermelha em solução aquosa. Em pH alto, esse cátion é convertido em outras espécies incolores (REVILLA, RYAN e MARTIN-ORTEGA, 1998). O fato do cátion flavílio ser estável em pH ácido levou a utilização de solventes contendo ácidos orgânicos ou minerais na extração de antocianinas de frutas e vegetais (MACHEIX, FLEURIET e BILLOT, 1990).

O uso de solventes contendo ácido fórmico ou clorídrico tem sido indicado para a extração de antocianinas de uvas (FERNANDEZ-LÓPEZ et al., 1992; REVILLA, RYAN e MARTIN-ORTEGA, 1998). Entretanto, o uso de solventes contendo mais que $1 \%$ de ácido clorídrico pode resultar, segundo REVILLA, RYAN e MARTIN-ORTEGA (1998), em hidrólise parcial das antocianinas aciladas e, conseqüentemente, na estimação incorreta do total de antocianinas. No caso de sucos de frutas e vegetais, a preparação das amostras é realizada por diluição com alcoóis acidificados, seguida ou não de filtração (FRANCIS, 1982).

Acetona também tem sido utilizada para extração de antocianinas em produtos de origem vegetal. Em comparação com a técnica que emprega metanol acidificado, a utilização de acetona permite extração mais eficiente e reprodutível. Também evita problemas com pectina e permite o uso de temperaturas mais baixas para concentração da amostra (GARCIA-VIGUERA, ZAFRILLA e TOMÁS-BARBERÁN, 1998).

Em vegetais e frutas frescas existem poucos compostos que podem absorver energia na região de absorção máxima das antocianinas (465 a $550 \mathrm{~nm}$ ). Desta forma, a quantificação de antocianinas é realizada por métodos espectrofotométricos baseados em medições simples de absorbância em comprimentos de onda adequados (WROLSTAD, 1976; JACKMAN e SMITH, 1996). 
Para amostras contendo mistura de antocianinas, as medidas de absorbância efetuadas num único valor de $\mathrm{pH}$ são proporcionais à concentração total de antocianinas. Entretanto, esse método está sujeito a interferências e não pode ser usado na presença de produtos escuros, originados a partir da degradação de açúcares ou da própria antocianina (JACKMAN, YADA e TUNG, 1987; JACKMAN e SMITH, 1996). Nesse caso, os métodos indiretos subtrativos ou diferenciais são os mais recomendados para a determinação da concentração de antocianinas (WROLSTAD, 1976).

Os métodos subtrativos são baseados na mudança de absorbância da amostra, no comprimento de onda máximo no visível, após branqueamento com sulfito de sódio ou peróxido de hidrogênio. A diferença entre a absorbância da amostra antes e depois do branqueamento é calculada. A concentração de antocianinas é obtida mediante curva de calibração, preparada com o extrato purificado do pigmento (JACKMAN e SMITH, 1996). A desvantagem desse método é que substâncias interferentes podem também ser descoloridas causando diminuição na absorbância da amostra e resultando em superestimativa da concentração do pigmento (FRANCIS, 1982).

Os métodos diferenciais têm sido os mais utilizados na determinação quantitativa das antocianinas. Esses métodos baseiam-se nas mudanças de absorbância resultantes da variação do $\mathrm{pH}$ das soluções e no fato das características espectrais dos produtos de degradação não serem alteradas por mudanças no pH (FRANCIS, 1982). Diferentes valores de $\mathrm{pH}$ têm sido empregados, porém o método mais comum mede a absorbância em pH 1,0 e 4,5 no mesmo comprimento de onda de absorção máxima (FULEKI e FRANCIS, 1968).

É importante ressaltar que o método diferencial quantifica as antocianinas monoméricas e que os resultados podem não estar relacionados com a intensidade de cor das amostras (WROLSTAD, 1976). Os pigmentos poliméricos vermelhos contribuem significativamente para a absorbância máxima das antocianinas e ainda apresentam cor em pH 4,5. As medidas das concentrações de antocianinas por esses métodos não correspondem à cor visual do produto, uma vez que a medida da forma colorida é feita em $\mathrm{pH} 1,0 \mathrm{em}$ que as antocianinas existem na forma do cátion flavílio vermelho. Em produtos como sucos de frutas, cujos valores de $\mathrm{pH}$ variam entre $2,5 \mathrm{e}$ 
4,0, a distribuição e a concentração dos cromóforos das antocianinas são diferentes (JACKMAN e SMITH, 1996).

WROLSTAD (1976) descreveu métodos para determinar a densidade de cor, a cor decorrente de antocianinas poliméricas e a porcentagem de contribuição de taninos e de antocianinas monoméricas para a cor. Esses métodos baseiam-se em cálculos e em poucas leituras de absorbância no pH do alimento. A densidade de cor é determinada pela soma das absorbâncias da amostra a 420 e $520 \mathrm{~nm}$. O primeiro comprimento de onda absorve os produtos de escurecimento e o segundo constitui o comprimento de máxima absorção das antocianinas. Assim, avalia-se a contribuição das antocianinas e também de seus produtos de degradação para a cor.

A cor polimérica corresponde à contribuição das antocianinas poliméricas e dos pigmentos marrons provenientes de escurecimento enzimático, reação de Maillard e degradação de antocianinas. Essa medida baseia-se no fato de que os pigmentos polimerizados são resistentes ao branqueamento com bissulfito. Desta forma, após a adição de bissulfito de potássio, a soma das absorbâncias nos comprimentos de onda de 420 e 520 nm corresponde à cor polimérica (WROLSTAD, 1976).

A análise quantitativa de antocianinas individuais requer separação e/ ou purificação prévia da mistura, que são usualmente realizadas por métodos cromatográficos. A purificação da amostra torna-se necessária, pois os solventes empregados na extração não são específicos para antocianinas e podem extrair diversos materiais (como outros compostos fenólicos e pectina). Esses contaminantes podem influenciar a estabilidade e a análise das antocianinas (JACKMAN e SMITH, 1996).

Inúmeros métodos cromatográficos são empregados para separar e analisar antocianinas em frutas. As cromatografias em papel (FRANCIS, 1985; MAZZA e VELIOGLU, 1992), em camada delgada (DUSSI, SUGAR e WROLSTAD, 1995) e a líquido de alta eficiência (GAO et al., 1997; MAZZA e VELOGLU, 1992) são exemplos dos métodos mais utilizados.

A separação das antocianinas tem ocorrido tradicionalmente por 
técnicas cromatográficas, especialmente por cromatografia em papel, empregando-se diferentes sistemas de solventes como fase móvel (FRANCIS, 1982). No entanto, a mais rápida e eficiente separação de misturas complexas de antocianinas é feita por cromatografia a líquido de alta eficiência (CLAE). A técnica não é destrutiva e, portanto, os picos separados podem ser coletados para análises posteriores. Além disso, a CLAE pode ser usada para separar e quantificar microgramas de antocianinas sem necessitar de extensa purificação preliminar das amostras (JACKMAN, YADA e TUNG, 1987).

A identificação de antocianinas de Vitis vinífera tem sido realizada satisfatoriamente com a utilização de CLAE acoplada à espectrometria de massa (EM). Essa técnica combina a eficiência da CLAE com a seletividade e sensibilidade do detector EM, permitindo a identificação de compostos individuais numa mistura complexa (BALDI et al., 1995). Outra técnica utilizada para análise de antocianinas é a eletroforese capilar, que apresenta excelente sensibilidade, alta resolução, baixo consumo de amostra e gasto mínimo de solventes. A ressonância magnética nuclear em uma ou duas dimensões também tem sido usada na elucidação estrutural de antocianinas (KONG et al., 2003).

\section{CONSIDERAÇÕES FINAIS}

As antocianinas apresentam baixa estabilidade em produtos industrializados, o que limita seu uso como corante natural em alimentos ou como constituinte de formulações farmacêuticas. Entre os principais fatores relacionados com a instabilidade das antocianinas durante o processamento de sucos podem ser citados aqueles associados à composição inicial da fruta, tal como o tipo de antocianina e a presença de certas enzimas. Fatores externos característicos do tipo de processamento como temperatura, luz e presença de oxigênio também interferem na estabilidade das antocianinas.

No caso particular do suco de uva, a composição em antocianinas é afetada significativamente por determinados tratamentos aos quais a uva e o mosto são submetidos como aquecimento, prensagem, pasteurização e tratamentos enzimáticos.

Outros estudos para avaliar e aumentar a estabilidade de antocianinas 
em alimentos processados são ainda necessários, visando maior aplicabilidade desses compostos como corantes em alimentos e bebidas, assim como a manutenção da qualidade e das propriedades nutricionais em alimentos naturalmente ricos em antocianinas.

\section{Abstract}

\section{ANTHOCYANIS IN GRAPE JUICE: COMPOSITION AND STABILITY}

In this review the anthocyanins composition and stability of grape juice were studied. Related aspects of several stages influence of processing in the degradation of anthocyanins were approached. A briefing about quantitative and qualitative analysis methods of anthocyanins also was presented. Besides the initial composition of raw material, the composition of anthocyanins in grape juice is influenced by several factors like $\mathrm{pH}$, temperature and presence of light and oxygen during the processing. More studies to evaluate and increase the stability of anthocyanins are still necessary looking for a better application of these compounds in processed foods.

KEY-WORDS: ANTHOCYANINS; GRAPE; GRAPE JUICE.

\section{REFERÊNCIAS}

1 ADAMS, J. B. Thermal degradation of anthocyanins with particular reference to the $3-$ glycosides of cyaniding. I. In acidified aqueous solution at $100^{\circ} \mathrm{C}$. Journal of Science and Food Agriculture, v. 24, p. 747-750, 1973.

2 ARAÚJO, J. M. A. Química de alimentos: teoria e prática. Viçosa: UFV, 1995. p. 279-295.

3 ASEN, S.; STEWART, R. N.; NORRIS, K. H. Copigmentation of anthocyanins in plant tissue and its effect on color. Phytochemistry, v. 11, p. 1139-1143, 1972.

4 BALDI, A. et al. HPLC/MS application to anthocyanins of Vitis vinifera L. Journal of Agriculture and Food Chemistry, v. 43, p. 2104-2109, 1995.

5 BOBBIO, P. A.; BOBBIO, F. O. Química do processamento de alimentos. 3. ed. São Paulo: Varela, 2001. p. 103-118.

6 BROUILLARD, R.; DUBOIS, J. E. Mechanism of the structural 
transformations of anthocyanins in aqueous media. Journal of American Chemistry Society, v. 99, p. 1359-1363, 1977.

7 BROUILLARD, R. Chemical structure of anthocyanins. In: MARKAKIS, P. (Ed.) Anthocyanins as food colors. New York: Academic Press, 1982. p. 1-39.

8 BROUILLARD, R. et al. The copigmentation reaction of anthocyanins: a micropobe for the structural study of aqueous solutions. Journal of American Chemistry Society, v. 111, p. 247-252, 1989.

9 DERGAL, S. B. Química de los alimentos. 3. ed. Nancalpon de Juárez: Longman de México, 1993. p. 388-397.

10 DUSSI, M. C.; SUGAR, D.; WROLSTAD, R. E. Characterizing and quantifying anthocyanins in red pears and the effect of light quality on fruit color. Journal of American Society for Horticultural Science, v. 120, p. 785-789, 1995.

11 FALCÃO, L. D. et al. Copigmentação intra e intermolecular de antocianinas: uma revisão. Boletim do CEPPA, v. 21, n. 2, p. 351-366, 2003.

12 FERNÁNDEZ-LÓPEZ, J. A. et al. Quantitative changes in anthocyanins pigments of Vitis vinifera cv. Monastrell during maturation. Journal of Science and Food Agriculture, v. 58, p. 153-155, 1992.

13 FRANCIA-ARICHA, F. M. et al. New anthocyanin pigments formed after condensation with flavonols. Journal of Agriculture and Food Chemistry, v. 45, p. 2262-2266, 1997.

14 FRANCIS, F. J. Analysis of anthocyanins. In: MARKAKIS, P. (Ed.) Anthocyanins as food colors. New York: Academic Press, 1982. p. 182-205.

15 FRANCIS, F. J. Detection of enocyanin in cranberry juice cocktail by color an pigment profile. Journal of Food Science, v. 50, p. 1640-1642, 1985.

16 FRANCIS, F. J. Food colorants: anthocyanins. Critical Review 
of Food Science and Nutrition, v. 28, p. 273-314, 1989.

17 FRANCIS, F. J. Anthocyanins and betalains: composition and applications. Cereal Foods World, v. 45, p. 208-213, 2000.

18 FULEKI, T.; FRANCIS, F. J. Quantitative methods for anthocyanins. 2. Determination of total anthocyanin and degradation index for cranberry juice. Journal of Food Science, v. 33, p. 78-83, 1968.

19 GARCIA-VIGUERA, C.; ZAFRILLA, P.; TOMÁS-BARBERÁN, F. A. The use of acetone as an extraction solvent for anthocyanins from strawberry fruit. Phytochemical Analysis, v. 9 , p. $274-277,1998$.

20 GAO, L. et al. Changes in anthocyanins and color characteristics of Pinot Noir wines during different vinification processes. Journal of Agriculture and Food Chemistry, v. 45 , p. 2003-2008, 1997.

21 GOLDY, R. G.; BALLINGER, W. E.; MANESS, E. P. Fruit anthocyanin content of some Euvitis $\times$ Vitis rotundifolia hybrids. Journal of American Society for Horticultural Science, v. 111, p. 955-959, 1986.

22 HAGIWARA, A. et al. Pronounced inhibition by a natural anthocyanin, purple corn color, of 2-amino-16-phenylimidazol $(4,5-$ b) pyridine (PhIP)-associated colorectal carcinogenesis in male F344 rats pretreated with 1,2-dimethylhydrazine. Cancer Letters, v. 171, p. 17-25, 2001.

23 HOFSOMMER, H. J. Determination of anthocyanins and carotinoids in fruit juices. Fruit Processing, v. 5, p. 90-93, 1995.

24 HRAZDINA, G. Anthocyanin composition of Concord grapes. Lebensm. Wiss. Technol., v. 8, p. 111-113, 1975.

25 IACOBUCCI, G. A.; SWEENY, J. G. The chemistry of anthocyanins, anthocyanidins, and related flavilium salts. Tetrahedron Letters, v. 39, p. 3005-3012, 1983.

26 JACKMAN, R. L.; YADA, R. Y.; TUNG, M. A. A review: 
separation and chemical properties of anthocyanins used for their qualitative and quantitative analysis. Journal of Food Chemistry, v. 11, p. 279-308, 1987.

27 JACKMAN, R. L.; SMITH, J. L. Anthocyanins and betalains. In: HENDRY, G. A. F.; HOUGHTON, J. D. (Eds.) Natural Food Colorants. $2^{\text {nd }}$ ed. Londres: Chapman \& Hall, 1996. p. 245309.

$28 \mathrm{KAMEI}, \mathrm{H}$. et al. Anti-tumor effect of methanol extracts from red and white wines. Cancer Biotherapy and Radiopharmacology, v. 13, p. 447-452, 1998.

29 KAPADIA, G. J. et al. Inhibition of 12 -O-tetradecanoylphorbol13-acetate induced Epstein virus early antigen activation by natural colorants. Cancer Letters, n. 115, p. 173 -178, 1997.

30 KIRCA, A.; ÖZKAN, M.; CEMEROGLU, B. Stability of black carrot anthocyanins in various fruit juices and nectars. Food Chemistry, v. 97, p. 598-605, 2006.

31 KONG, J. M. et al. Analysis and biological activities of anthocyanins. Phytochemistry, v. 64, p. 923-933, 2003.

32 KUSKOSKI, E. M. et al. Actividad antioxidante de pigmentos antociánicos. Ciência e Tecnologia de Alimentos, v. 24, p. 691-693, 2004.

33 MACHEIX, J. J.; FLEURIET, A.; BILLOT, J. Fruit phenolics. Boca Raton: CRC Press, 1990. 378 p.

34 MALACRIDA, C. R. Compostos fenólicos e alguns parâmetros físico-químicos em suco de uva. Belo Horizonte, 2003. 120 f. Dissertação (Mestrado em Ciência de Alimentos), Departamento de Alimentos, Faculdade de Farmácia, Universidade Federal de Minas Gerais.

35 MARKAKIS, P. Stability of anthocyanins in foods. In: MARKAKIS, P. (Ed.) Anthocyanins as food colors. New York: Academic Press, 1982. p. 163-180.

36 MAZZA, G.; BROUILLARD, R. Recent developments in the stabilization of anthocyanins in food products. Food 
Chemistry, v. 25, p. 207-225, 1987.

37 MAZZA, G.; VELIOGLU, Y. S. Anthocyanins and other phenolics compounds in fruits of red-flesh apples. Food Chemistry, v. 43 , p. 113-117, 1992.

38 MAZZA, G.; MINIATI, E. Anthocyanins in fruits, vegetables and grains. Boca Raton: CRC Press, 1993. 362 p.

39 MAZZA, G. Anthocyanins in grape and grape products. Critical Review of Food Science and Nutrition, v. 35, p. 341-371, 1995.

40 MESCHTER, E. L. Effects of carbohydrates and other factors on strawberry products. Journal of Agriculture and Food Chemistry, v. 1, p. 579-583, 1954.

41 OSAWA, Y. Copigmentation of anthocyanins. In: MARKAKIS, P. (Ed.) Anthocyanins as food colors. New York: Academic Press, 1982. p. 41-67.

42 PALAMIDIS, N.; MARKAKIS, P. Stability of grape anthocyanin in a carbonated beverage. Journal of Food Science, v. 40, p. 1047-1049, 1975.

43 REVILLA, E.; RYAN, J. M.; MARTIN-ORTEGA, G. Comparison of several procedures used for the extraction of anthocyanins from red grape. Journal of Agriculture and Food Chemistry, v. 46, p. 4592-4597, 1998.

44 RIBÉREAU-GAYON, P. The anthocyanins of grapes and wines. In: MARKAKIS, P. (Ed.) Anthocyanins as food colors. New York: Academic Press, 1982. p. 209-242.

45 ROMMEL, A.; WROLSTAD, R. E.; HEATHERBELL, D. A. Blackberry juice and wine: processing and storage effects on anthocyanin composition, color and appearance. Journal of Food Science, v. 57, p. 385-391, 1992.

46 SARNI-MANCHADO, P. S. et al. Stability and color of unreported wine anthocyanin-derived pigments. Journal of Food Science, v. 61 , p. $938-941,1996$. 
47 SHAHIDI, F.; NACZK, M. Food phenolics: sources, chemistry, effects and applications. Lancaster: Technomic, 1995. 331 p.

48 SISTRUNK, W. A.; GASCOIGNE, H. L. Stability of color in Concord grape juice and expression of color. Journal of Food Science, v. 48, p. 430-435, 1983.

49 SOMERS, T. C.; EVANS, M. E. Spectral evaluation of young wines: anthocyanin equilibrium, total phenolics, free and molecular sulfur dioxide "chemical age". Journal of Science and Food Agriculture, v. 28, p. 279-281, 1977.

50 STARR, M. S.; FRANCIS, F. J. Effect of metallic ions on color and pigment content of cranberry juice cocktail. Journal of Food Science, v. 38, p. 1043-1046, 1973.

51 TIMBERLAKE, C. F.; BRIDLE, P. Anthocyanins. In: WALFORD, J. (Ed.) Developments in food colours. London: Applied Science Publishers, 1980. p. 115-149.

52 TRESSLER, D. K.; PEDERSON, C. S. Preservation of grape

53 VAN BUREN, J. P. et al. A comparative study on the anthocyanin pigment composition in wines derived from hybrid grapes. American Journal of Enology and Viticulture, v. 21, p. 117$121,1970$.

54 WANG, J.; SPORNS, P. Analysis of anthocyanins in red wine and fruit juice using MALDI-MS. Journal of Agriculture and Food Chemistry, v. 47, p. 2009-2015, 1999.

55 WANG, C. J. et al. Protective effect of Hibiscus anthocyanins against tert-butyl hidroperoxideinduced hepatic toxicity in rats. Food and Chemical Toxicology, v. 38, p. 411-416, 2000.

56 WIGHTMAN, J. et al. Some effects of processing enzymes on anthocyanins and phenolics in Pinot Noir and Cabernet Sauvignon wines. American Journal of Enology and Viticulture, v. 48, p. 39-48, 1997.

57 WROLSTAD, R. E. Colors and pigment analysis in fruit products. Corvallis: Oregon Agricultural Experimental Station, 1976. $17 \mathrm{p}$. 
58 YOUDIM, K. A.; MARTIN, A.; JOSEPH, J. A. Incorporation of elderberry anthocyanins by endothelial cells increases protection against oxidative stress. Free Radical Biology \& Medicine, v. 29, p. 51-60, 2000. 